Gelanggang Olahraga: Jurnal Pendidikan Jasmani dan Olahraga

Volume 3, Nomor 1, Juli-Desember 2019

e-ISSN : $2597-6567$

p-ISSN : 2614-607X

DOI : https://doi.org/10.31539/jpjo.v3i1.867

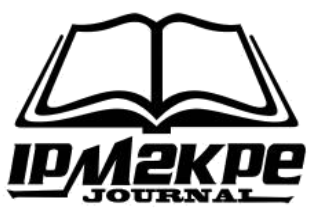

\title{
VALIDITAS MODUL BOLA TANGAN BAGI MAHASISWA PENDIDIKAN JASMANI KESEHATAN DAN REKREASI STKIP PGRI LUBUKLINGGAU
}

\author{
Popalri $^{1}$, Azizil Fikri ${ }^{2}$ \\ STKIP PGRI Lubuklinggau ${ }^{1,2}$ \\ popalri89@gmail.com ${ }^{1}$
}

\begin{abstract}
ABSTRAK
Penelitian ini bertujuan untuk mengembangkan modul bola tangan untuk mahasiswa Pendidikan Jasmani Kesehatan dan Rekreasi STKIP PGRI Lubuklinggau yang valid. Penelitian ini menggunakan rancangan dan pendekatan penelitian pengembangan (R\&D) Research and Development, dimana penelitian ini mengembangkan produk bahan ajar berupa modul permainan bola tangan, untuk penelitian ini hanya dibatasi sampai tahap pengembangan pada tahap validasi. Uji validitas dalam tahap ini merupakan validitas teoritik yaitu validasi yang dilakukan oleh para ahli dibidangnya yang terdiri dari tiga orang validator. Validasi yang dilakukan meliputi validasi kebahasaan, validasi materi/isi dan validasi media/desain. Hasil penelitian modul bola tangan yang dikembangkan memenuhi kriteria kevalidan dengan nilai validitas kebahasaan sebesar $94 \%$, validitas media/desain sebesar $90 \%$ dan nilai validitas isi/materi sebesar $94 \%$ yang dapat diartikan sangat valid. Simpulan, modul bola tangan sangat valid digunakan dalam proses pembelajaran mahasiswa.
\end{abstract}

Kata Kunci: Modul, Bola Tangan

\begin{abstract}
This study aims to develop a handball module for valid Physical Health and Recreation Education STKIP PGRI Lubuklinggau students. This study uses a research and development research and development $(R \& D)$ approach, in which this research develops teaching material products in the form of handball game modules, for this research is only limited to the development stage at the validation stage. Validity test in this stage is a theoretical validity that is validation carried out by experts in their field consisting of three validators. Validation includes language validation, material / content validation and media / design validation. The results of the developed handball module meet the validity criteria with a language validity value of $94 \%$, media / design validity of $90 \%$ and a content / material validity value of $94 \%$ which can be interpreted to be very valid. In conclusion, the handball module is very valid to be used in the learning process of students.
\end{abstract}

Keywords: Module, Handball 


\section{PENDAHULUAN}

Permainan bola tangan merupakan cabang olahraga yang sebenarnya sudah lama dikenal di Indonesia terbukti Permainan bolatangan pernah diselenggarakan di PON ke 2 di Jakarta tahun 1951 dan Pekan Olahraga Mahasiswa ke 5 di Medan tahun 1960 dan sampai saat sekarang bola tangan merupakan salah satu matakuliah yang diajarkan di Lembaga Pendidikan Tinggi Kependidikan Program Studi keolahragaan. Keberadaannya olahraga bola tangan kurang berkembang karena jenis permainan yang kurang populer, minim sosialisasi dan organisasi yang masih belum berkembang di daerah-daerah sehinga hanya berpusat di kota-kota besar. Berdasarkan sejarah berdirinya olahraga bola tangan telah berusia sangat tua. sebuah fakta menunjukkan seseorang memainkan bola tangan jauh lebih awal daripada permainan sepak bola. Permainan bola tangan yang dimainkan pada masa Yunani kuno merupakan sebuah isyarat terciptanya olahraga bola tangan modern (IHF, 2012).

Bola tangan dimainkan diatas lapangan dengan panjang 40 meter x 20 meter. masing-masing tim terdiri atas 6 pemain dan 1 penjaga gawang. Waktu yang digunakan yaitu 2 × 30 menit. Setiap tim terdiri dari 12 pemain. Namun, hanya 7 pemain yang ada di lapangan termasuk dengan seorang penjaga gawang. Selebihnya merupakan pemain pengganti selama pertandingan.

Permainan bola tangan terdiri atas beberapa teknik dasar seperti warmingup, drib-bling, passing, shooting, possitioning, attacking exercise, defencing exercise, dan fast break exercise namun dalam permainan hanya tiga teknik dasar yang paling sering digunakan, dianta-ranya; (1) teknik dribbling yaitu upaya pemain untuk membawa bola mendekati daerah pertahanan lawan dengan cara memantulkan bola ke lantai, (2) teknik passing yaitu upaya memberikan bola kepada teman dengan menggunakan satu atau dua tangan, (3) tek-nik shooting atau menembak bola ke gawang.

Hasil penelitian Nursantiko dan Rahadyan (2016) pengembangan media video tutorial dapat meningkatkan teknik dasar bola tangan. Sedangkan penelitian Yulita (2016) pengembangan permainan bola tangan gawang pantul dapat meningkatkan pembelajaran penjasorkes. Kemudian hasil penelitian Ranchman dan Amirullah (2016) hasil penelitian 100\% permainan menyenangkan dan dapat membuat anak senang bergerak, 90,82\% permainan mudah dilakukan, 96,94\% dapat memahami peraturan dengan baik, $93,88 \%$ siswa taat pada peraturan yang berlaku $10.20 \%$ siswa mengalami kesulitan, 98,98\% siswa merasa suka dengan perlatan yang digunakan, 95,92\% dapat melakukan kerjasama dan 6,74\% merasa takut melakuka permainan.Hasil penelitian Rohman (2018) metode pembelajaran permainan Bola tangan dengan menggunakan latihan ladder drill hop scotch dapat meningkatkan kemampuan Agility bermain bola tangan.

Penelitian ini menekankan pada validitas modul bola tangan, sehingga dapat digunakan bagi mahasiswa dalam mempelajari teknik bermain bola tangan. Modul bola tangan yang dirancang, dapat digunakan oleh dosen dan mahasiswa penjaskesrek. Pembuatan modul bola tangan berfungsi sebagai alat bantu dalam pelaksanaan pembelajaran. Modul bola tangan yang dibuat ini diharapkan dapat membantu mahasiswa dalam memahami materi sehingga memperoleh hasil yang baik. Penelitian yang dilakukan bertujuan untuk mengetahui validitas dari modul bola tangan yang dikembangkan. 


\section{KAJIAN TEORI Modul}

Modul pada dasarnya adalah sebuah bahan ajar yang disusun secara sistematis dengan bahasa yang mudah dipahami oleh peserta didik sesuai dengan tingkat pengetahuan dan usia mereka, agar mereka dapat belajar sendiri (mandiri) dengan bantuan atau bimbingan yang minimal dari pendidik (Prastowo, 2011). Kemudian Daryanto (2013) modul adalah sebuah buku yang ditulis dengan tujuan agar peserta didik dapat belajar secara mandiri tanpa atau dengan bimbingan guru, sehingga modul berisi paling tidak tentang segala komponen dasar bahan ajar.

Berdasarkan pendapat para ahli diatas dapat diambil kesimpulan modul yaitu bahan ajar yang disusun secara sistematis dengan satu pokok bahasan yang mudah dipahami oleh peserta didik, sehingga peserta didik dapat menyerap informasi baik secara mandiri maupun dengan bantuan pendidik. Modul mempunyai beberapa karakteristik tertentu, misalnya berbentuk unit pengajaran terkecil dan lengkap, berisi rangkaian kegiatan belajar yang dirancang secara sistematis, berisi tujuan belajar yang dirumuskan secara jelas dan khusus, memugkinkan siswa belajar mandiri dan merupakan realisasi perbedaan individual.

\section{Bola Tangan}

Bola tangan (handball) adalah olahraga beregu di mana dua regu dengan masing-masing 7 pemain (6 pemain dan 1 penjaga gawang) berusaha memasukkan sebuah bola ke gawang lawan. Permainan ini mirip dengan sepak bola, tapi cara memindahkan bola adalah dengan tangan pemain, bukan kaki. (Asosiasi Bola Tangan Indonesia - bolatangan.or.id/home.html).

Bola tangan adalah olahraga tim yang dimainkan oleh dua tim baik lakilaki atau perempuan yang masing-masing terdiri dari tujuh pemain (6 fielder dan 1 kiper). Para pemain diperbolehkan untuk memainkan bola menggunakan tangan mereka, tetapi mereka tidak boleh memainkan bola menggunakan kaki mereka. Tujuan dari permainan ini adalah untuk mencetak gol dan mengantisipasi terjadinya gol. Tim yang mencetak skor lebih banyak dalam waktu yang ditentukan memenangkan pertandingan. Permainan ini dimainkan pada tempo yang sangat tinggi dan kontak fisik yang cukup ketat. Oleh karena itu fair play harus dijunjung tinggi. Bola tangan dapat dimainkan di dalam atau di luar ruangan pada lapangan berukuran 40 × 20 meter.

\section{METODE PENELITIAN}

Penelitian ini menggunakan rancangan pendekatan penelitian pengembangan atau termasuk kedalam penelitian pengembangan. Dalam penelitian ini dikembangkan modul bola tangan. Pengembangan dalam penelitian ini dadaptasi menjadi model 4-P lebih runtun dan adanya tahap validasi dan uji coba menjadikan draft yang dihasilkan lebih sempurna Menurut Thiangarajan dalam Trianto (2011) pengembangan model four-D terdiri dari 4 tahap utama yaitu: (1) define (menetukan materi), (2) design (perancangan), (3) develop (pengembangan), dan (4) dessiminate (penyebaran). Namun dalam penelitian ini dibatasi oleh peneliti dalam tahap pengembangan produk. Tahap pengembangan bertujuan memperoleh draft modul yang sudah diperbaiki melalui hasil validasi yang diikuti dengan revisi dan uji coba dengan siswa. Tahap ini meliputi validasi 
oleh pakar yang diikuti dengan revisi. Sedangkan subjek dalam penelitian adalah mahasiswa semester 2 penjaskesrek STKIP PGRI Lubuklinggau.

\section{Tahap Define (Pendefinisian)}

Tahap pendefinisian terdapat lima langkah pokok yaitu : pra penelitian, analisis siswa, analisis konsep, analisis tugas dan perumusan tujuan pembelajaran.

\section{Tahap Design (Perancangan)}

Tahap perancangan bertujuan untuk menyiapkan prototype modul dengan langkah pemilihan format dan desain awal modul. Modul yang dikembangkan disesuaikan dengan KI dan KD yang ditetapkan.

\section{Tahap Develop (Pengembangan)}

Tahap pengembangan bertjuan memperoleh draft produk berupa modul yang sudah diperbaiki melalui hasil validasi yang diikuti dengan revisi dan uji coba dengan siswa. Uji validtias pada tahap ini merupakan validitas teoritik yaitu validasi yang dilakukan oleh para ahli dibidangnya. Karakteristik yang akan divalidasi yaitu, kebahasaan, materi, dan desain/media. Validator tersebut menganalisis modul yang dirancang dan memberikan saran serta masukan pada rancangan modul. Validator disini memvalidasi sesuai dibidangnya masingmasing sehingga modul yang dihasilkan dikatakan valid. Simulasi yaitu kegiatan mengoprasionalkan rencana pengajaran, dan uji coba terbatas dengan siswa yang sesungguhnya. Hasil tahap ini digunakan sebagai dasar revisi penggunakan produk di lapangan. Langkah selanjutnya yaitu uji coba lebih lanjut dengan siswa yang sesuai dengan kelas sesungguhnya.

\section{Tahap Disseminate (Penyebaran)}

Tahap penyebaran dilakukan dengan penggunaan modul yang telah dikembangkan pada skala yang lebih besar yaitu kelas lain yang bertujuan untuk menguji efektivitas penggunaan perangkat di dalam kegiatan pembelajaran.

\section{HASIL PENELITIAN}

Validasi kebahasaan untuk memvalidasi modul bola tangan yaitu diberikan angket terbuka sebanyak 7 pertanyaan. Selain itu terdapat juga kolom saran yang diberikan guna perbaikan modul bola tangan yang divalidasi. Untuk hasil validasi kebahasaan dapat dijelaskan pada tabel berikut;

Tabel.

Tanggapan Ahli Kebahasaan

\begin{tabular}{ccl}
\hline Rentang Skor & \multicolumn{1}{c}{ Persentase } & \multicolumn{1}{c}{ Kategori } \\
\hline $30-35$ & $\mathrm{P} \geq 85,71 \%$ & Sangat Baik \\
\hline $24-29$ & $68.57 \% \leq \mathrm{P}<84.71 \%$ & Baik \\
\hline $18-23$ & $51,42 \% \leq \mathrm{P}<67.57 \%$ & Cukup \\
\hline $12-17$ & $34.28 \% \leq \mathrm{P}<50.42 \%$ & Kurang Sesuai \\
\hline $6-11$ & $17.14 \% \leq \mathrm{P}<33.28 \%$ & Sangat Tidak Baik \\
\hline
\end{tabular}


Jumlah pertanyaan $=7$

Kategori kriteria $=5$

Skor maksimal $=7 \times 5=35$

Skor minimal $=7 \mathrm{x} 1=7$

Skor yang diperoleh $=33$

Rentang nilai $=\frac{35-7}{5}=\frac{28}{5}=5.6$

Persentase $=\frac{33}{35} \times 100=94 \%$

Kesimpulan penghitungan komponen kelayakan kebahasaan termasuk dalam kategori Sangat Baik, dengan persentase 94\%. Selain kebahasaan selanjutnya yaitu evaluasi ahli desain/media modul bola tangan yang mana dapata kita lihat pada tabel 2 dibawah ini :

Tabel. 2

Tanggapan Penyajian Ahli Media/Desain

\begin{tabular}{ccl}
\hline Rentang Skor & Persentase & \multicolumn{1}{c}{ Kategori } \\
\hline $42-50$ & $\mathrm{P} \geq 84 \%$ & Sangat Baik \\
\hline $33-41$ & $66 \% \leq \mathrm{P}<83 \%$ & Baik \\
\hline $23-32$ & $48 \% \leq \mathrm{P}<65 \%$ & Cukup \\
\hline $14-23$ & $30 \% \leq \mathrm{P}<47 \%$ & Kurang Sesuai \\
\hline $6-14$ & $12 \% \leq \mathrm{P}<29 \%$ & Sangat Tidak Baik \\
\hline
\end{tabular}

Jumlah pertanyaan $=10$

Kategori kriteria $=5$

Skor maksimal $=10 \times 5=35$

Skor minimal $=10 \times 1=7$

Skor yang diperoleh $=45$

Rentang nilai $=\frac{50-10}{5}=\frac{40}{5}=8$

Persentase $=\frac{45}{35} \times 100=90 \%$

Kesimpulan komponen kelayakan desain termasuk dalam kategori Sangat Baik, Dengan persentase $90 \%$.

Validator ahli materi adalah untuk mengetahui layak dan akurat tidaknya materi teks yang digunakan. Berdsarkan hasil dari validasi oleh ahli materi dapat dilihat pada tebel 3 berikut:

Tabel.3

Tanggapan Ahli Materi

\begin{tabular}{lll}
\hline \multicolumn{1}{c}{ Rentang Skor } & \multicolumn{1}{c}{ Persentase } & \multicolumn{1}{c}{ Kategori } \\
\hline $6-11$ & $\mathrm{P} \geq 85,71 \%$ & Sangat Baik \\
\hline $24-29$ & $68.57 \% \leq \mathrm{P}<84.71 \%$ & Baik \\
\hline $18-23$ & $51,42 \% \leq \mathrm{P}<67.57 \%$ & Cukup \\
\hline $12-17$ & $34.28 \% \leq \mathrm{P}<51 \%$ & Kurang Sesuai \\
\hline $6-11$ & $17.14 \% \leq \mathrm{P}<33.28 \%$ & Sangat Tidak Baik \\
\hline
\end{tabular}


Jumlah pertanyaan $=7$

Kategori kriteria $=5$

Skor maksimal $=7 \times 5=35$

Skor minimal $=7 \mathrm{x} 1=7$

Skor yang diperoleh $=33$

Rentang nilai $=\frac{35-7}{5}=\frac{28}{5}=5.6$

Persentase $=\frac{33}{35} \times 100=94 \%$

Kesimpulan komponen kelayakan isi/materi termasuk dalam kategori sangat baik, dengan persentase 94\%. Hasil dari ketiga validator secara keseluruhan dapat dilihat pada rekapitulassi dibawah in, penilaian dari ketiga ahli validasi terhadap modul bola tangan yang sudah dijelaskan menunjukkan penilaian yang baik. Rekapitulasi hasil keseluruhan dari 3 validator dapat dilihat pada perhitungan pada tabel 4 dibawah ini:

Tabel.4

Rekapitulasi Tanggapan Ahli

\begin{tabular}{lllll}
\hline No & Validator & Skor & Persentase & Kategori \\
\hline 1 & Bahasa & 33 & 94 & Valid \\
\hline 2 & Desain & 45 & 90 & Valid \\
\hline 3 & Isi/Materi & 33 & 94 & Valid \\
\hline & Total & 111 & $92.7 \%$ & valid \\
\hline
\end{tabular}

Jumlah pertanyaan $=24$

Kategori kriteria $=5$

Skor maksimal $=24 \times 5=120$

Skor minimal $=24 \times 1=24$

Skor yang diperoleh $=111$

Rentang nilai $=\frac{120-24}{5}=\frac{278}{5}=19.2$

Persentase $=\frac{33}{35} \times 100=92,7 \%$

Kesimpulan keseluruhan komponen validasi ahli termasuk dalam kategori Sangat Baik. Dengan persentase 92,7\%.

\section{PEMBAHASAN}

Modul bola tangan yang dirancang untuk dapat digunakan oleh dosen dan mahasiswa penjaskesrek STKIP PGRI Lubuklinggau. Pembuatan modul bola tangan berfungsi sebagai alat bantu dalam pelaksanaan pembelajaran. Modul bola tangan yang dibuat ini diharapkan dapat membantu mahasiswa dalam memahami materi sehingga memperoleh hasil yang baik. Penelitian yang dilakukan bertujuan untuk mengetahui validitas dari modul bola tangan yang dikembangkan.

Validtias dari suatu alat evaluasi harus ditinjau dari karakteristik tertentu. Suatu alat dikatakn valid apabila alat tersebut mampu mengevaluasi apa yang seharusnya dievaluasi (Suherman, 1993), sedangkan Menurut Plomp (2007) karakteristik dari produk yang dikatakan valid apabila ia merefleksikan jiwa pengetahuan (state of the art knowledge). Hal inilah yang dikatakan dengan validasisi (content validiy). Selanjutnya, komponen-komponen produk tersebut 
harus konsisten satu sama lain (validitas konstruk). Oleh sebab itu, validasi yang dilakukan terhadap modul bola tangan pada penelitian ini menekankan pada validitas isi (content validity) dan validitas konstruksi (construct validity). Berdasarkan analisis data penilaian validasi dari validator, maka validitas modul bola tangan yang dikembangkan tergolong sangat valid.

\section{SIMPULAN}

Pengembangan modul bola tangan untuk mahasiswa Penjaskesrek STKIP PGRI Lubuklinggau yang dikembangkan memenuhi kriteria kevalidan. Hal ini memberikan gambaran bahwa modul pembelajaran bola tangan yang dikembangkan valid dan dapat digunakan dalam pembelajaran permainan bola tangan.

\section{DAFTAR PUSTAKA}

Abdurrochim, M., Ranchman, H., A. (2016). Pengembangan Model Permainan Bola Tangan Untuk Anak Usia Sekolah Dasar Kelas Atas. Jurnal Keolahragaan. 4(1), 60-73.

Daryanto. (2013.) Menyusun Modul Bahan Ajar untuk Persiapan Guru dalam mengajar. Yogyakarta: Gava Media.

IHF. (2012). International Handball Federation Rules of the Game. Basel Switszerland.

Nursantiko, D., R. (2016). Pengembangan Media Video Tutorial Teknik Dasar Bola Tangan Untuk Mahasiswa PJKR FIK UNY. Jurnal Student UNY. $5(10)$

Plomp, T., Nieveen, N. (Eds). (2007). An Introduction to Educational Design Research. Enschede: Netherlands Institute for Curriculum Development (SLO).

Prastowo, A. (2011). Panduan Kreatif Membuat Bahan Ajar Inovatif. Jogyakarta: Diva Press.

Rohman, U. (2018). Metode Pembelajaran Permainan Bola Tangan Dengan Mnggunakan Latihan Ladder Drill Hop Scotch Pengaruhnya Terhadap Kemampuan Agility Bermain Bola Tangan. Jurnal FKIP Unipa Surabaya. 14(26), 136-143.

Suherman, E. (1993). Evaluasi Proses Dan Hasil Belajar Matematika. Jakarta: Universitas Terbuka.

Trianto. (2010). Pengantar Penelitian Pendidikan bagi Pengembangan Profesi Pendidikan dan Tenaga Kependidikan. Surabaya: Prenada Media Group.

Yulita. (2016). Pengembagan Permainan Bola Tangan Gawang Pantul Untuk Pembelajaran Penjasorkes. Jurnal Penjaskesrek. 3(2), 24-31. 